\title{
The Effects of the World War I on the Development of the Modern Concept of Trauma
}

\section{Sefa $B^{*}$}

Ibn Haldun University Head of Counseling Psychology and Guidance Department Istanbul, Turkey

*Corresponding author: Sefa B, Ibn Haldun University Head of Counseling Psychology and Guidance Department Istanbul, Turkey, Email: sefabulut22@gmail.com

\section{Review Article}

Volume 4 Issue 1

Received Date: November 27, 2019

Published Date: March 02, 2020

DOI: $10.23880 / \mathrm{mhrij}-16000137$

\section{Abstract}

The modern concept of trauma and posttraumatic stress diagnosis has evolved to a large degree from documentations of soldiers' pre-and-post war experiences, and observations. The purpose of this paper is to investigate the effects of the first Word War on the development of the concept posttraumatic stress disorder at the turn of the century. Even though soldiers' war histories and stories were popular in previous wars, the moving point for understanding and classification of traumatic stress gained more importance and systematic investigation after WW-I. Due to the large number of drafted soldiers, and veterans and the death count, WW-I had a great impact on a large number of soldiers, their families, and the society as a whole. During the First World War attention was focused for the first time on the illness known as "shell shock" or "traumatic neurosis." Due to military needs and compensation reasons, treatment options were searched for in many parts of the world. Traumatic experience was named "shell shock" and was thought to be a neurological disorder caused by explosive bombing.

Keywords: History of PTSD; War and Trauma; Military Trauma; Shell Shock

\section{Introduction}

During the time of WW-I, the British army fought on four continents in almost every part of the world. Large numbers of troops became unable to fight and developed the symptoms of conversion hysteria, apparent stupor, and over arousal. They were treated as inpatients for a considerably long time period; however many did not recover. The first studies were conducted by neurologists who believed the illness was due to exposure to explosive chemical materials and its impact on the brain [1]. In the following days, unsucessesful treatments led the psychiatrists involved in the treatment process to establish new units called NYD-P (not yet diagnosed-psychiatric) units. By 1917, 8,000 British soldiers were receiving pensions due to psychiatric disabilities [2]. It was during the war and right after the war that the first large scale numbers of cases were documented in detailed description.

\section{William Rivers' Two Revolutionary Studies and Papers}

After WWI, British Army Psychiatrist William H. Rivers, who worked at the Craig Lockart War Hospital, Edinburgh, conducted extensive observations and interviews with discharged veteran soldiers who fought at Gallipoli (Gelibolu) with Turkish soldiers. He published two revolutionary papers, focusing on two main factors causing war neuroses with regard to traumatic experience. The first element was predisposition to nervousness due to individual and family history. The second contributor was the quantity and the extent of the individual's anxiety level. He was one of the earlier pioneers who drew attention to predisposition (genetic) tendencies in the formation of trauma. Rivers classified war neuroses into three groups. In the first group, the disorder was demonstrated in physical form, such as paralysis, mutism, blindness, deafness, 


\section{Mental Health \& Human Resilience International Journal}

anaesthesia, or convulsive seizure. This group of symptoms fits today's modern diagnosis of conversion hysteria. In the second group, patients suffered from lack of physical and mental energy. They had sleep disturbances, and digestion problems; felt more depressed, restless, and irritable; and had tics and speech problems. This group was described as having "neurasthenia." The third group manifested symptoms that were completely psychical (psychological) in nature. The most obvious symptoms were mental instability and restlessness with alternations of depression and excitement similar to manic-depressive insanity. Rivers argued that in all three groups, patients were in very much like a psychotic state, but they were held legally accountable for their actions. In his etiology of trauma, he used psychoanalytic language and explained the dynamics of trauma with the concepts of suggestibility, regression, sublimation, and conflict. He also elaborated on the socio-cultural contexts of trauma etiology by explaining the difference between private soldiers' and officers' reactions to trauma. Rivers used the term "functional nervous disorder" and was careful not to use the term "hysteria." He wrote: "It will be much more satisfactory if it is possible to find a term based on the etiological rather than the therapeutical aspect of the syndrome". Furthermore, he reported that neurasthenia and psychasthenia were no longer scientifically valuable diagnoses and the nomenclature of functional nervous disorders was not a satisfactory description. Finally, he concluded that anxiety was both the main factor in causation and at the same time one of the leading symptoms. However, he warned that the term "anxiety" was used by Freud and psychoanalysts in a narrower sense than he meant. Rivers believed that "If the nature and causation of anxiety neurosis were more fully understood, it would be possible to intervene at an earlier stage and save many..."

In his second paper explained treatment options for soldiers who had been in France and suffered from warneuroses. Rivers mentioned four case studies and divided repression into categories [3]. The first type is a mental blackout that makes the mental content of memories inaccessible in the conscious level. Modern psychology literature also acknowledges that some PTSD patients forget some of the main components of the trauma. In this sense Rivers was very close to today's knowledge (DSM- IV TR, Criterion C3: inability to recall an important aspect of the trauma). The second type of repression was more deliberately initiated and was an attempt to distinguish mere inaccessibility to memory from a special kind of separation from the rest of the mental content, which corresponds closely with disassociation. In his paper he used suppression as an active and voluntary process to remove painful memories from consciousness. This was also about the dissociative states (DSM- IV TR, Criterion B3). According to Rivers, the dynamic of war-neurosis was explainable is dissociative terms. All of the four cases under his care demonstrated extreme sleep disturbance, nightmares, unpleasant memories, avoidance behavior and intrusion of thoughts. Before these soldiers came under his care, they were advised not to talk about war experiences, not to think about them, and not to read newspapers about the war. However, the harder they tried to suppress and forget during the day, the more they were terrorized in their sleep. As a treatment option, he prescribed to his patients not to try to banish their war experiences, anxieties, painful memories, and other intrusional thoughts, feelings, and smells, but instead to talk about them. He advised his patients to give up the practice of repression, to read the papers, talk occasionally about the war, and gradually accustom themselves to thinking, and hearing about, war experiences. As time progressed, soldiers were more able to handle their memories at a tolerable level, their sleep patterns became more stable, and they had fewer nightmares. He cautioned that "moderation is necessary in talking, reading and thinking about war experience." Rivers explained this process as the principle of "catharsis." It allowed the patients to reintegrate the suppressed or dissociated experiences into their personality. In addition to catharsis, he also suggested that in some cases, re-education of patients might be necessary. Re-education undoubtedly played a significant part, making possible the cessation of repression, and helping the patient to adjust himself to the environment, contributing to his recovery or improvement. Rivers confirmed that the presentations were similar to those of neurotic illness in peacetime, and tended to name all of them "anxiety neuroses." Rivers, like others, did not propose a new specific posttraumatic illness [4].

The Shell Shock Inquiry, conducted in the United States Army by , was in line with River's position and recommended that the term "shell shock" be abandoned. At that time, the common belief was that trauma precipitated a variety of mental illnesses that usually resolved themselves unless they solidified into a chronic case of one of the diagnosed illnesses. It was not believed that trauma produced a single durable clinical presentation. This view dominated the field for many years.

Collected a detailed depiction of traumatic neurosis. $\mathrm{He}$ pointed out conversion hysteria symptoms, marked trembling, and impotence in war veterans [5]. In addition, hyper arousal, sleep disturbances, vivid nightmares, and irritability were very common stress reactions among soldiers. His descriptions are very similar to current knowledge of PTSD. He emphasized the compensationseeking and malingering effect of the trauma survivor's behavior. Rado explained the chronological psychodynamics of trauma in four phases: pre-traumatic face, traumatic period, early posttraumatic period and late posttraumatic period. Rado disagreed with Freud's notion of trauma and 


\section{Mental Health \& Human Resilience International Journal}

shifted the paradigm from organic based theories to a more psychogenic point of view. He strongly argued that trauma is caused by psychological functioning. He coined the term "traumatophobia," which is the transformation of a neurosis from a fear of war into a fear of the responsibilities in life. Further, he was the first to mention the predisposing factors and trauma assessment techniques.

Woods wrote that after WW-II, the problems of soldiers who participated in the war gained more attention and publicity so that their psychological problems were more systematically and empirically investigated and the first longitudinal studies were conducted. Even if these studies had some methodological deficiencies, they were valuable in terms of showing the long term effects of traumata [6].

Due to the nature of war and the need to replace the soldiers in war zone and post-war compensation claims, Word War I was a striking point in the history of traumatology. However, most of the studies were done with adult survivors or veterans. Even though the first war produced an ample number of displaced and wounded people, widows' and orphans, children and women did not receive any particular attention until World War II.

\section{References}

1. Schelenger JA, Caddle WE, Woods MG (1993) Posttraumatic stress disorder. In: Sutker PB, Adams HE (Eds.), Comprehensive Handbook of Psychopathology, Plenum Press, New York, pp: 145-165.

2. Mott FW (1917) mental hygiene and shell shock. British Medical Journal 2(2950): 39-42.

3. Rado S (1942) Patodynamics and treatment of traumatic war neurosis (traumatophobia). Psychosomatic Medicine 4: 362-368.

4. Rivers WH (1918) War neurosis and military training. Mental Hygiene 2: 513-533.

5. Rivers WH (1920) Instinct and the unconscious: A contribution to a biological theory of the psychoneuroses.

6. Salmon TW (1917) The care and treatment of mental diseases and war neuroses" Shell Shock" in the British Army. War Work Committee of the National Committee of Mental Hygiene, New York. 